\title{
Outcome of Children with Marked Changes in Maternal Screening Tests
} and Normal Karyotype

Kai Muru ${ }^{1,2 \#}$, Mari-Anne Vals ${ }^{1,3 \#}$, Mari Sitska ${ }^{2}$, Karin Asser ${ }^{4}$, Pille Tammur $^{2}$, Olga Zilina ${ }^{2,5}$, Tiia Reimand ${ }^{1,2,6}$ and Katrin Ounap $^{1,2 *}$

${ }^{1}$ Department of Pediatrics, University of Tartu, Estonia

${ }^{2}$ Department of Genetics, United Laboratories, Tartu University Hospital, Estonia

${ }^{3}$ Tartu University Hospital, Children's Clinic, Estonia

${ }^{4}$ Tartu University Hospital, Radiology Clinic, Estonia

5 Institute of Molecular and Cell Biology, University of Tartu, Estonia

${ }^{6}$ Department of Human Biology and Genetics, Institute of Biomedicine and Translational Medicine, University of Tartu, Estonia

\# These authors contributed equally

\section{Abstract}

Objective: To investigate whether chromosomally normal fetuses with marked changes in maternal serum markers and first trimester ultrasound NT marker have an increased risk of congenital anomalies or delayed development at 2 years of age.

Methods: Screening tests of 5257 pregnant women were analyzed during a one-year period. Significant changes in biochemical and/or ultrasound markers were documented in 138 pregnant women, whereas positive risk calculation for chromosomal anomalies was evident in 74 of them, who were included in our study. Postnatal study group included 35 children born from mothers with marked changes in screening tests.

Results: Among the 74 pregnant women, a structural or genetic abnormality was diagnosed in 16 cases (21.6\%), fetal death occurred in 12 cases (16.2\%) and child was healthy at the age of 2 years in 31 cases $(41.9 \%)$. In $3 / 4$ of the cases, a pathology was diagnosed prenatally, while the remaining $1 / 4$ were discovered postnatally. Four children had with congenital anomalies and/or syndromes: two had congenital heart disease - atrial septal defect and ventricular septal defect with patent ductus arteriosus, one Silver-Russell syndrome and one congenital adrenal hyperplasia. It was not possible to get the final information about outcome in 15 cases $(20.3 \%)$.

Conclusions: Children born to these mothers should be actively followed by a pediatrician or clinical geneticist for additional investigations after birth as they have a risk of $5.4 \%$ of having a congenital or genetic abnormality.

Keywords: Maternal serum screening; Biochemical markers; Nuchal translucency; Adverse pregnancy outcome; Outcome; Prenatal screening

\section{Introduction}

First and second trimester screening for aneuploidies has been routinely and widely used in prenatal care in the whole world [1-3] and for 15 years in Estonia as well [4]. Estonia is a small country with 1.3 million inhabitants and approximately 14,000 live births per year. In Estonia, the second trimester screening program with 2 markers a-fetoprotein (AFP) and Human Chorionic Gonadotropin (HCG) was introduced in 1999, and with 3 markers (AFP, HCG and unconjugated oestriol (uE3) in 2003, first trimester ultrasound screening for Nuchal Translucency (NT) was established in 2001, and combined screening in first trimester, including pregnancy associated plasma protein-A (PAPP-A), free $\beta$-Human Chorionic Gonadotropin (free $\beta-H C G$ ) and NT, in 2005 [4].

Although the primary aim of the screening is to identify pregnancies at risk of aneuploidy, significant changes in markers may give insight into other adverse pregnancy outcomes. Several studies have shown associations between low first trimester serum markers PAPP-A or free $\beta-\mathrm{HCG}$, increased ultrasound marker (NT), and adverse perinatal outcome [5-12].

Associations with changes in second trimester serum markers (AFP, HCG, and uE3) and adverse perinatal outcome have also been shown in different studies [13-19]. There are several studies about the long-term outcome of children with increased NT. Some of these showed a higher risk for developmental disorders [20,21], whereas more recent studies do not show an increased risk for developmental delay at 2 years of age $[11,12,22]$.

This study reflects the results of small homogenous population. The aim of our study was to investigate whether chromosomally normal fetuses with marked changes $(<0.25$ multiples of the median $(\mathrm{MoM})$ or $>3.0 \mathrm{MoM}$ ) in maternal first or second trimester serum markers and first trimester ultrasound marker NT $(\geq 3 \mathrm{~mm})$ have an increased risk of congenital or genetic anomalies or delayed development at 2 years of age.

\section{Material and Methods}

\section{Prenatal study group}

The present study was based on the screening test analysis of 5257 pregnant women during a one-year period (from 16th February 2009 to 15th February 2010) in Tartu University Hospital, which covers approximately $1 / 3$ of all prenatal screening tests performed in Estonia. All women were Caucasians in age range from 16 to 46 years; two thirds were from Estonian origin and one third from Slavic origin. Other nationalities occurred very seldom $(<1 \%)$. According to the Estonian prenatal screening program, if possible a contingent screening strategy for prenatal screening is used [4]. All first trimester serum (1525 women) and ultrasound screening (1589 women), and second trimester screening test (4410 women) results were analyzed (Figure 1).

*Corresponding author: Katrin Ounap, Department of Genetics, United Laboratories, Tartu University Hospital, 2 L. Puusepa Street, Tartu 51014, Estonia, Tel: 3727319 490; Fax: + 3727319 484; E-mail: katrin.ounap@kliinikum.ee

Received December 04, 2013; Accepted December 24, 2013; Published December 26, 2013

Citation: Muru K, Vals MA, Sitska M, Asser K, Tammur P, et al. (2013) Outcome of Children with Marked Changes in Maternal Screening Tests and Normal Karyotype. Genetics 3: 123. doi:10.4172/2161-1041.1000123

Copyright: ( 2013 Muru K, et al. This is an open-access article distributed under the terms of the Creative Commons Attribution License, which permits unrestricted use, distribution, and reproduction in any medium, provided the original author and source are credited. 
Maternal serum PAPP-A, free $\beta$-HCG, AFP, HCG and uE3 levels were measured by a solid-phase, competitive chemiluminescent enzyme immunoassay method using the commercially available radioimmunoassay kit Immulite 2000 (distributed by Siemens Medical Solutions Diagnostics Immulite DPC). The risks for Down and Edwards syndrome were calculated by Prisca software version 4.0 (distributed by Siemens Medical Solutions Diagnostics Immulite DPC). Gestational age was calculated from the first day of the last menstrual period and confirmed by ultrasonography. All measured values were adjusted for maternal weight, smoking, multiple pregnancies, in vitro fertilization (IVF) and gestational age using MoM. Marked changes in markers were defined as above 3.0 MoM for serum markers AFP and HCG, below $0.25 \mathrm{MoM}$ for PAPP-A, free $\beta$-HCG, HCG and $\mathrm{uE} 3$ and $\geq 3 \mathrm{~mm}$ for NT.

Seventy four women with positive risk calculation by Prisca software for chromosomal anomalies and marked changes in biochemical and/ or ultrasound markers were counseled by a geneticist and were included in our study (Figure 1).

Fetal pathology was defined as pregnancy loss (miscarriage or fetal death), aneuploidy or anatomical defect detected on ultrasound examination.

\section{Postnatal study group}

Altogether 45 mothers (Figure 1) who were consulted by geneticist and to whom additional prenatal investigations were suggested (ultrasound and/or fetal chromosomal analysis), met the criteria previously described, had live births and were included in the postnatal study group. Ten of these women refused to bring their child to the follow-up. Thus, the postnatal study group included 35 children born from mothers with marked changes in screening tests.

Children were examined by a pediatrician or clinical geneticist around the age of 2 years. Collected data included obstetrical

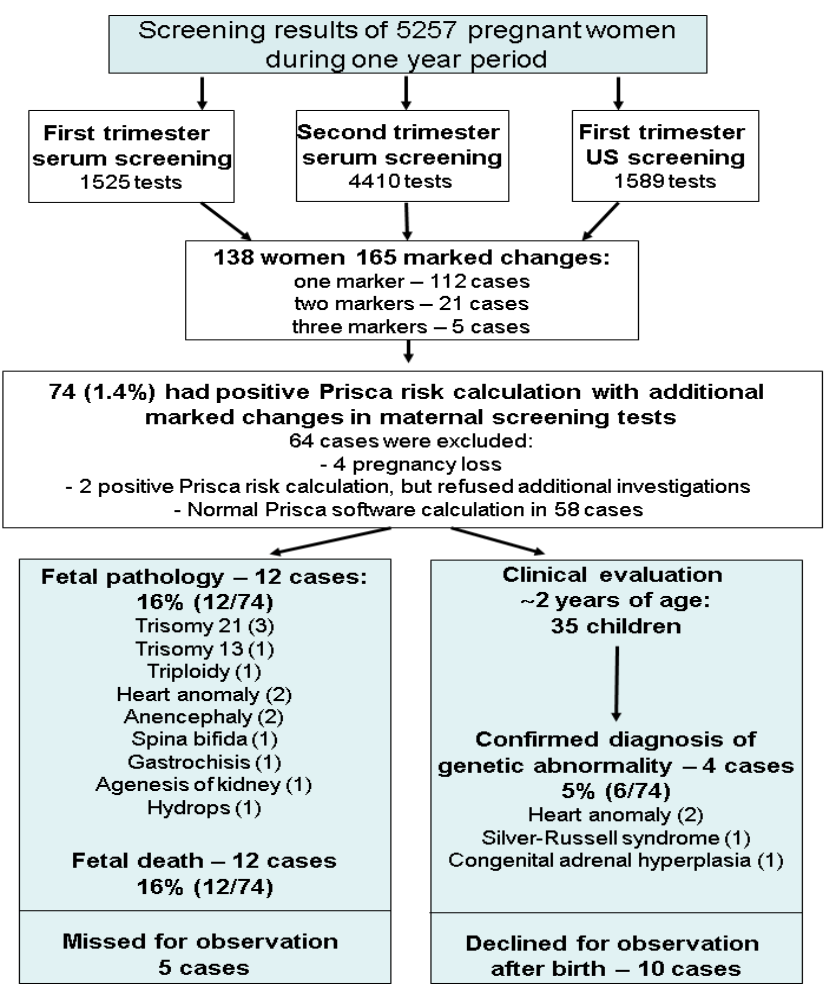

Figure 1: Flow diagram showing pregnancy and postnatal outcome. information about pregnancy and birth, gestational age and growth parameters at birth, child's health problems including diagnosed congenital malformations in neonatal period or later, maternal health problems prior pregnancy and family history. On examination, child's weight, height and head circumference were measured, developmental milestones were assessed and dysmorphic features were systematically looked for. Estonian age- and gender-specific growth curves were used to evaluate growth parameters at birth and later.

If growth failure, delayed developmental milestones, more than three dysmorphic features and/or congenital malformations were diagnosed, further diagnostic tests were indicated. The additional investigations depended on clinical picture of the child and these included Illumina chromosomal microarray analysis, metabolic investigations and in one case genetic analysis for the Noonan syndrome. Screening for chromosomal rearrangements was performed using HumanCNV370Quad or HumanCytoSNP-12 Beadchips (Illumina Inc., San Diego, CA, USA). Genotypes were called by Bead Studio v.3.1 or Genome Studio v2009.1 software (Illumina Inc.), and further CNV analysis and breakpoint mapping was conducted with Quanti SNP v1.1 or v2.1 software. Metabolic investigations included amino acid, organic acid and acylcarnitine analysis.

All the study parts were approved by the Ethics Committee on Human Research at the University of Tartu. Informed consent was obtained from all pregnant women who participated in this study.

\section{Results}

\section{Prenatal study group}

Altogether 5257 pregnant women pass through prenatal screening tests during the study period and in 240 of them had positive screening result (4.6\%). Additional postulated marked changes in markers were present in 138 of them. A total of 165 significant changes were documented in these 138 women. Deviations in only one marker were observed in 112 cases, in two markers in 21 cases and in three markers in five cases (Figure 1). AFP elevation and/or low $\mathrm{uE3}$ were the most frequent changes in solitary markers. In $80 / 138$ cases $(1.4 \%$ of all tested women), the Prisca risk calculation was positive for chromosomal disorders or neural tube defects. From these 80 women 74 were referred to genetic counseling as four pregnancies had already spontaneously aborted by that moment and two women refused to come to genetic counseling.

In 58/138 women, the Prisca risk calculation was negative for chromosomal disorders and, therefore, they were not actively evaluated further. However, we have one genetic service center in Estonia and at least three years later the children, born from these 58 pregnancies, have no clinical indication to do any chromosomal analysis, so we may be quite sure, that these tests were truly negative cases.

Among the 74 counseled women, a structural or genetic pathology was diagnosed in 12 cases (16\%) during prenatal diagnostics (ultrasound and/or fetal karyotyping): trisomy 21 (3 cases), trisomy 13 ( 1 case), triploidy ( 1 case), anencephaly ( 2 cases), spina bifida ( 1 case), gastrochisis (1 case), renal agenesis (1 case), critical heart anomaly (1 case), and fetal hydrops ( 1 case) (Table 2 ). Fetal death was diagnosed in 12 cases (16\%) (Figure 1$)$.

Increased NT during first trimester ultrasound screening was documented in nine cases (in all cases the NT measured between 3-6 $\mathrm{mm}$ ). During subsequent prenatal investigations, chromosomal anomalies were diagnosed in two cases and a critical heart defect (severe left ventricle hypoplasia) in one case, in all these cases pregnancy 
Citation: Muru K, Vals MA, Sitska M, Asser K, Tammur P, et al. (2013) Outcome of Children with Marked Changes in Maternal Screening Tests and Normal Karyotype. Genetics 3: 123. doi:10.4172/2161-1041.1000123

Page 3 of 6

\begin{tabular}{|c|c|}
\hline \multicolumn{2}{|c|}{$\begin{array}{c}74 \text { pregnant women }(1.4 \%) \text { with positive Prisca risk calculation and postulated marked changes in biochemical markers and/or US } \\
\text { During a one-year evaluation period among } 5257 \text { pregnant women }\end{array}$} \\
\hline Prenatally confirmed genetic or structural abnormality & 12 cases $(16.2 \%)$ \\
\hline Fetal death & 12 cases $(16.2 \%)$ \\
\hline Postnatally confirmed genetic or structural abnormality & 4 cases $(5.4 \%)$ \\
\hline Healthy child at the age of 2 years & 31 cases $(41.9 \%)$ \\
\hline Lost during prenatal or postnatal evaluation & 15 cases $(20.3 \%)$ \\
\hline
\end{tabular}

Table 1: Outcome of pregnancies with postulated marked changes in prenatal screening.

\begin{tabular}{|c|c|c|c|c|c|c|c|}
\hline NT (mm) & PAPP-A (MoM) & free $\beta$-HCG (MoM) & AFP (MoM) & HCG (MoM) & uE3 (MoM) & diagnosed pathology & pregnancy outcome \\
\hline 1.7 & 0.23 & 0.51 & 1.72 & 1.33 & 0.13 & trisomy $13^{*}$ & terminated \\
\hline 6 & 1 & 2.4 & & & & trisomy 21 & terminated \\
\hline \multirow[t]{2}{*}{4.4} & 0.22 & 4.04 & & & & trisomy 21 & terminated \\
\hline & & & 0.53 & 2.44 & 0.18 & trisomy 21 & terminated \\
\hline 2.2 & 0.07 & 0.09 & 0.34 & 0.02 & 0.27 & triploidy & terminated \\
\hline \multirow[t]{4}{*}{3.7} & 0.9 & 0.36 & & & & $\mathrm{HLHS}^{* * *}$ & terminated \\
\hline & & & 4.97 & 0.62 & 0.3 & anencephaly & terminated \\
\hline & & & 12.01 & 1.87 & 0.23 & anencephaly & terminated \\
\hline & & & 7.67 & 0.52 & 1.31 & gastroschisis & terminated \\
\hline \multirow[t]{3}{*}{1.4} & 0.24 & 0.14 & & & & fetal hydrops ${ }^{* *}$ & terminated \\
\hline & & & 4.19 & 1.1 & 1.44 & bilateral renal agenesis & terminated \\
\hline & & & 5.12 & 0.78 & 1.36 & neural tube defect & terminated \\
\hline
\end{tabular}

*risk for trisomy 21 and trisomy 18 was negative

**karyotype 46,XY

***HLHS - hypoplastic left heart syndrome, karyotype 46,XY

Table 2: Prenatally diagnosed pathology and screening results.

\begin{tabular}{|c|c|c|c|c|c|c|c|c|}
\hline Column1 & $\mathbf{n}$ & premature birth & postmature birth & SGA & LGA & $\begin{array}{c}\text { weight/height } 3-97 \mathrm{P} \text { at } \\
\text { the age of } 2 \text { years }\end{array}$ & $\begin{array}{l}\text { delayed milestones at } \\
\text { the age of } 2 \text { years }\end{array}$ & $\begin{array}{l}\text { Congenital or } \\
\text { genetic disease }\end{array}$ \\
\hline $\mathrm{NT} \geq 3.0 \mathrm{~mm}(3.0-4.5 \mathrm{~mm})$ & 5 & 1 & 0 & 0 & 1 & 5 & 0 & 0 \\
\hline $\begin{array}{c}\text { extreme value in one } \\
\text { marker }\end{array}$ & 20 & 2 & 4 & 2 & 0 & 19 & 2 & $2^{*}$ \\
\hline \multirow[t]{2}{*}{$\begin{array}{c}\text { extreme value in } \geq 2 \\
\text { markers }\end{array}$} & 10 & 1 & 0 & 4 & 0 & 7 & 3 & $2^{\star *}$ \\
\hline & 35 & $4(11.4 \%)$ & $4(11.4 \%)$ & 6 & 1 & 31 & $5(14.3 \%)$ & $4(11.4 \%)$ \\
\hline
\end{tabular}

SGA - small for gestational age

LGA - large for gestational age

* - one congenital heart disease, one congenital adrenal hyperplasia

** - one congenital heart disease, one Silver-Russell syndrome

Table 3: Postnatal outcome in children born after marked changes in maternal screening tests during pregnancy.

was terminated. One mother declined to come into the follow-up consultation with child after birth.

\section{Postnatal study group}

Postnatal study group consisted of 35 children (Figure 1, Tables 3 and 4). At assessment the mean age of children was 23.4 months. Four children had been diagnosed with congenital anomalies and/or syndromes: two had Congenital Heart Disease (CHD) - atrial septal defect and ventricular septal defect with patent ductus arteriosus, one Silver-Russell syndrome (SRS) and one Congenital Adrenal Hyperplasia (CAH). Five children (14\%) were evaluated to have delayed developmental milestones. Twelve children (34\%) had more than 3 dysmorphic features. On follow-up examination, further diagnostics was additionally indicated in eight children, one mother refused of investigations. All results of performed analyses were normal. Children with delayed developmental milestones will be followed up by pediatrician.

Among the offspring of 74 pregnant women (1.4\% of all screened women) with postulated marked changes and positive Prisca risk calculation, prenatal or postnatal structural or genetic abnormality was diagnosed in 16 cases (21.6\%), fetal death occurred in 12 cases $(16.2 \%)$ and child was healthy at the age of 2 years in 31 cases (41.9\%) (Table 1 ).
Structural or genetic abnormalities were diagnosed prenatally in $3 / 4$ of cases and postnatally in $1 / 4$ of cases. It was not possible to get the final information about pregnancy outcome in 15 cases (20.3\%).

\section{Discussion}

Abnormal levels of serum markers and elevated NT used in prenatal screening for the most common aneuploidies have been associated with adverse pregnancy outcomes [5,8,11,14,17,23-26]. In our study group a favorable outcome was found in $41.9 \%$ of cases and structural or genetic abnormality was diagnosed in $21.6 \%$ of cases (Table 1 and Figure 1). In $16.2 \%$ of cases fetal death occurred and $20.3 \%$ of the cases were lost during the evaluation period. A limitation of our study was a small population. Strict follow-up group with extensive follow-up is possible in bigger centers. Nevertheless, a correlation between marked changes in prenatal screening markers and adverse pregnancy outcome can still be seen.

The rate of CHD in our postnatal study group was $5.7 \%$. Two CHD were diagnosed postnatally (atrial septal defect and ventricular septal defect with patent ductus arteriosus). Both children were born as small for gestational age, had more than three dysmorphic features and delayed milestones on examination. Nevertheless, both had normal 
Citation: Muru K, Vals MA, Sitska M, Asser K, Tammur P, et al. (2013) Outcome of Children with Marked Changes in Maternal Screening Tests and Normal Karyotype. Genetics 3: 123. doi:10.4172/2161-1041.1000123

Page 4 of 6

\begin{tabular}{|c|c|c|c|c|c|c|c|c|c|c|c|c|}
\hline Initials & $\begin{array}{c}\text { Age at } \\
\text { assessment } \\
\text { (months) }\end{array}$ & $\begin{array}{l}\text { Full } \\
\text { term } \\
\text { birth }\end{array}$ & $\begin{array}{l}\text { Birth weight } \\
10^{\text {th }}-90^{\text {th }} \\
\text { percentiles }\end{array}$ & \begin{tabular}{|c|} 
Weight at \\
assessment $3^{\text {rd }}$ \\
$97^{\text {th }}$ percentiles
\end{tabular} & $\begin{array}{l}\text { Height at } \\
\text { assessment } 3^{\text {rd }} \text { - } \\
97^{\text {th }} \text { percentiles }\end{array}$ & $\begin{array}{c}\text { Delayed } \\
\text { milestones }\end{array}$ & $\begin{array}{c}\geq 3 \text { dysmorphic } \\
\text { features }\end{array}$ & $\begin{array}{c}\text { Congenital } \\
\text { malformations }\end{array}$ & Karyotype & $\begin{array}{c}\mathrm{NT} \geq 3 \\
\mathrm{~mm}\end{array}$ & $\begin{array}{l}\text { Changes } \\
\text { in serum } \\
\text { markers }^{*}\end{array}$ & $\begin{array}{c}\text { Further } \\
\text { diagnostics }\end{array}$ \\
\hline S.S & 21 & $\begin{array}{l}\text { Post } \\
\text { term }\end{array}$ & + & + & + & & & & & & 1 & \\
\hline G.V & 24 & + & + & $>97$ & $>97$ & + & & & $46, X Y$ & & 2 & \\
\hline EG.N & 17 & $\begin{array}{l}\text { Post } \\
\text { term }\end{array}$ & + & + & + & & & & $46, X X$ & & 1 & \\
\hline J.J & 25 & + & + & + & + & & & & & & 1 & \\
\hline KH.L & 18 & + & + & + & + & & & & & & 2 & \\
\hline T.S & 22 & + & + & + & + & + & & & & & 1 & \\
\hline A.A & 21 & + & + & + & + & & + & & & & 1 & \\
\hline LL.H & 28 & + & + & $<3$ & + & & & & $46, X X$ & & 1 & \\
\hline M.R & 31 & Preterm & + & + & + & & & & & & 2 & \\
\hline R.R & 26 & + & SGA & + & + & & & & $46, X Y$ & & 1 & \\
\hline M.L & 23 & + & + & + & + & & & & & & 2 & \\
\hline A.T & 27 & + & + & + & + & & & & & & 1 & \\
\hline ML.P & 23 & + & + & + & + & & & & $46, X X$ & & 1 & \\
\hline M.K & 26 & + & + & + & + & & + & & & & 1 & \\
\hline R.T & 30 & + & + & + & & & + & & $46, X Y$ & & 1 & \\
\hline L.A & 20 & + & SGA & + & + & & & & & & 1 & \\
\hline R.V & 24 & + & + & + & + & & & & $46, X Y$ & & 1 & \\
\hline K.H & 20 & Preterm & SGA & $<3$ & + & + & + & ASD & $46, X X$ & & 2 & + \\
\hline M.H & 24 & + & + & + & + & & & & $46, X X$ & + & & \\
\hline E.M & 23 & + & SGA & + & + & & + & & $46, X X$ & & 1 & \\
\hline K.T & 26 & + & + & + & + & & + & & & & 2 & + \\
\hline T.T & 20 & + & + & + & + & & & & & & 1 & \\
\hline M.S & 21 & + & + & + & + & & & & $46, X X$ & & 1 & \\
\hline HM.A & 19 & + & + & + & + & & & & $46, X X$ & + & & \\
\hline E.J & 26 & + & + & + & + & & & & $46, X X$ & & 1 & \\
\hline M.K & 20 & $\begin{array}{l}\text { Post } \\
\text { term }\end{array}$ & + & + & + & & & & $46, X Y$ & & 1 & \\
\hline J.A & 21 & $\begin{array}{l}\text { Post } \\
\text { term }\end{array}$ & + & + & + & & & & $46, X Y$ & & 1 & \\
\hline K.Š & 28 & Preterm & + & + & + & & + & & & + & & \\
\hline E.S & 33 & + & + & + & + & & + & & $46, X X$ & + & & + \\
\hline MM.K & 22 & + & SGA & + & + & + & + & VSD, PDA & $46, X X$ & & 1 & + \\
\hline $\mathrm{K} . \mathrm{V}$ & 23 & + & + & + & + & & + & & $46, X X$ & & 1 & + \\
\hline S.O & 20 & + & LGA & + & + & & + & & $46, X Y$ & + & & + \\
\hline R.K & 21 & + & + & + & + & & & & & & 1 & + \\
\hline M.M & & + & + & & & & & $\mathrm{CAH}$ & $46, X Y$ & & 1 & + \\
\hline AK.K & & Preterm & SGA & & & + & + & SRS & $46, X X$ & & 3 & \\
\hline
\end{tabular}

SGA=Small for Gestational Age; LGA=Large for Gestational Age

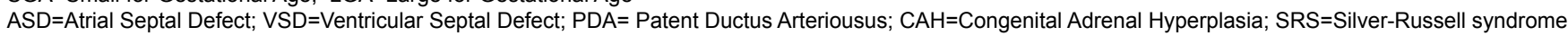
* previously described changes in first and second trimester screening, number indicating how many markers were affected

Table 4: The data of 35 evaluated cases: the age of evaluation, the results of clinical evaluation and the information of additional investigations.

karyotypes on prenatal testing and also normal Illumina chromosomal microarray analysis on examination. These children have had surgical repair of $\mathrm{CHD}$ and are still under cardiologist's follow-up. As the incidence of CHD may vary among studies depending on the timing of echocardiograms and the population included, their defects can be classified as moderate lesions, which together with severe CHD have an average incidence of 6 per 1000 live births [27]. Both children have the commonest forms of CHD. In addition, to our knowledge, at least one heart anomaly (left ventricle hypoplasia) with normal karyotype and no 22q11.2 microdeletion was diagnosed prenatally and the pregnancy was ended due to CHD. In this case, fetal NT was $3.6 \mathrm{~mm}$. The relationship between increased NT and CHD has been described and a recently published meta-analysis found that approximately $44 \%$ of major CHD in fetuses with normal karyotype have NT more than 2.5 $\mathrm{mm}$ [28]. Among our study group 9 fetuses with $\mathrm{NT} \geq 3 \mathrm{~mm}$ and only one case with major $\mathrm{CHD}$ were found. If we exclude the two cases with fetal chromosomal anomalies, then only one of 7 fetuses (14\%) with $\mathrm{NT} \geq 3 \mathrm{~mm}$ had CHD. As for the other two postnatally diagnosed CHD cases, the NT was $1.8 \mathrm{~mm}$ in one child, and one child did not have the NT scan during its fetal life. Nevertheless, fetuses with increased NT should be screened for major CHD during pregnancy.

Five children belong to the postnatal subgroup with increased NT. Three of them had more than three dysmorphic features but none had delayed developmental milestones or structural defects. Similar associations between increased NT and normal longterm neurodevelopmental outcomes are described in several other studies $[11,12,22]$. At the same time, five children $(14 \%)$ in postnatal subgroup with marked changes in maternal serum markers had delayed milestones at the age of 2 years. Nevertheless, we cannot make any conclusions about the association between serum markers and developmental outcome of children as our postnatal study group is small, affected serum markers were different and the evaluation of 
development is based on questioning the mothers and the examiners' subjective opinions.

In addition to previously described CHD, we had two children with postnatally diagnosed genetic disorders in our study group. We describe the changes in maternal serum markers and postnatal outcomes of these cases.

\section{A child in postnatal study group with SRS syndrome}

Patient's mother's first trimester screening marker levels were low (PAPP-A $0.31 \mathrm{MoM}$ and free $\beta$-HCG $0.13 \mathrm{MoM}$ ), NT was $1.5 \mathrm{~mm}$. In the second trimester screening test, the markers were also low (AFP 0.57 MoM, HCG 0.18 MoM, uE3 0.09 MoM). Fetal karyotype was $46, \mathrm{XX}$. The pregnancy was ended on the 31 st gestational week via Cesarean section due to fetal distress, intrauterine growth restriction and oligohydramnion. Both birth weight and length were $<3$ rd percentiles, head circumference was appropriate for gestational age. Illumina chromosomal microarray analysis showed $\sim 1.3-\mathrm{Mb}$ duplication in chromosomal region 11p15.5 which is inherited from the mother. The patient has the characteristic phenotype for the SRS syndrome, including postnatal growth failure, which is probably one cause for the delayed developmental milestones.

\section{A child in postnatal study group with CAH}

Patient's mother's first trimester screening marker levels were in the normal range (PAPP-A 0.59 MoM and free $\beta$-HCG $1.58 \mathrm{MoM}$, NT was $1.8 \mathrm{~mm}$ ), but she had a high risk for trisomy 21 (1:82). She wanted to perform the second trimester screening test as well before making a final decision about invasive procedures. In the second trimester screening test, the risk for trisomy 21 was also high (1:15) and uE3 was very low (0.15 MoM). Fetal karyotype was normal - 46,XY, and ultrasound investigation in second trimester showed normal fetal development. Child was born from normal birth at term with normal birth weight and length, he adapted without any problems. After birth measurement of 17-OH-progesterone revealed marked elevation (95.7 $\mathrm{nmol} / \mathrm{L}$ ) and $\mathrm{CAH}$ was diagnosed. The diagnosis was confirmed by DNA analysis, which showed compound heterozygosity: there was a chimeric gene involving the CYP21A2 gene and a pseudogene in one allele, and the deletion of exon 3 of CYP21A2 was determined in the second allele. At the age of two years he was a normally developed boy.

\section{Summary}

This study does not add any novel information to the field. Still, our study supports the fact that prenatal screening tests are valuable not only for aneuploidy screening, but also may be predictors for other structural or genetic abnormalities. Children born to these mothers should be actively followed by a pediatrician or clinical geneticist for additional investigations after birth as they have a risk of $5.4 \%$ of having a congenital or genetic abnormality.

\section{Acknowledgment} 8175

This study was supported by Estonian Science Foundation grant GARLA

\section{References}

1. Nicolaides $\mathrm{KH}$ (2011) Screening for fetal aneuploidies at 11 to 13 weeks. Prenat Diagn 31: 7-15

2. Wright D, Bradbury I, Cuckle H, Gardosi J, Tonks A, et al. (2006) Three-stage contingent screening for Down syndrome. Prenat Diagn 26: 528-534.

3. Boyd PA, Devigan C, Khoshnood B, Loane M, Garne E, et al. (2008) Survey of prenatal screening policies in Europe for structural malformations and chromosome anomalies, and their impact on detection and termination rates for neural tube defects and Down's syndrome. BJOG 115: 689-696.
4. Muru K, Sitska M, Asser K, Ehrenberg A, Karro H, et al. (2010) Prospective experience with contingent screening strategy for Down syndrome in Estonia. $J$ Community Genet 1: 133-138.

5. Spencer K, Cowans NJ, Avgidou K, Nicolaides KH (2006) First-trimester ultrasound and biochemical markers of aneuploidy and the prediction of impending fetal death. Ultrasound Obstet Gynecol 28: 637-643.

6. Spencer K, Cowans NJ, Molina F, Kagan KO, Nicolaides KH (2008) Firsttrimester ultrasound and biochemical markers of aneuploidy and the prediction of preterm or early preterm delivery. Ultrasound Obstet Gynecol 31: 147-152.

7. GoetzI L, Krantz D, Simpson JL, Silver RK, Zachary JM, et al. (2004) Pregnancyassociated plasma protein A, free beta-hCG, nuchal translucency, and risk of pregnancy loss. Obstet Gynecol 104: 30-36.

8. Goetzl L (2010) Adverse pregnancy outcomes after abnormal first-trimester screening for aneuploidy. Clin Lab Med 30: 613-628.

9. Dugoff L, Hobbins JC, Malone FD, Porter TF, Luthy D, et al. (2004) Firsttrimester maternal serum papp-a and free-beta subunit human chorionic gonadotropin concentrations and nuchal translucency are associated with obstetric complications: A population-based screening study (the faster trial). Am J Obstet Gynecol 191: 1446-51.

10. Krantz D, Goetzl L, Simpson JL, Thom E, Zachary J, et al. (2004) Association of extreme first-trimester free human chorionic gonadotropin-beta, pregnancyassociated plasma protein $\mathrm{A}$, and nuchal translucency with intrauterine growth restriction and other adverse pregnancy outcomes. Am J Obstet Gynecol 191 1452-1458.

11. Miltoft CB, Ekelund CK, Hansen BM, Lando A, Petersen OB, et al. (2012) Increased nuchal translucency, normal karyotype and infant development. Ultrasound Obstet Gynecol 39: 28-33.

12. Senat MV, Bussières L, Couderc $S$, Roume J, Rozenberg $P$, et al. (2007) Long-term outcome of children born after a first-trimester measurement of nuchal translucency at the 99th percentile or greater with normal karyotype: a prospective study. Am J Obstet Gynecol 196: 53.

13. Kang JH, Farina A, Park JH, Kim SH, Kim JY, et al. (2008) Down syndrome biochemical markers and screening for preeclampsia at first and second trimester: correlation with the week of onset and the severity. Prenat Diagn 28: 704-709.

14. Huang T, Owolabi T, Summers AM, Meier C, Wyatt PR (2005) The identification of risk of spontaneous fetal loss through second-trimester maternal serum screening. Am J Obstet Gynecol 193: 395-403.

15. Chandra S, Scott H, Dodds L, Watts C, Blight C, et al. (2003) Unexplained elevated maternal serum alpha-fetoprotein and/or human chorionic gonadotropin and the risk of adverse outcomes. Am J Obstet Gynecol 189 775-781.

16. Sayin NC, Canda MT, Ahmet N, Arda S, Süt N, et al. (2008) The association of triple-marker test results with adverse pregnancy outcomes in low-risk pregnancies with healthy newborns. Arch Gynecol Obstet 277: 47-53.

17. Summers AM, Huang T, Meier C, Wyatt PR (2003) The implications of a false positive second-trimester serum screen for Down syndrome. Obstet Gynecol 101: 1301-1306.

18. Spaggiari E, Ruas M, Dreux S, Valat AS, Czerkiewicz I, et al. (2013) Management strategy in pregnancies with elevated second-trimester maternal serum alpha-fetoprotein based on a second assay. Am J Obstet Gynecol 208 303.

19. Alleman BW, Smith AR, Byers HM, Bedell B, Ryckman KK, et al. (2013) A proposed method to predict preterm birth using clinical data, standard maternal serum screening, and cholesterol. Am J Obstet Gynecol 208: 472

20. Adekunle O, Gopee A, el-Sayed M, Thilaganathan B (1999) Increased firs trimester nuchal translucency: Pregnancy and infant outcomes after routine screening for down's syndrome in an unselected antenatal population. $\mathrm{Br}$ Radiol 72: 457-60.

21. Baumann C, Delagarde R, Vuillard E, Oury JF (2005) [Long-term follow-up of children with increased nuchal translucency and normal karyotype]. J Gynecol Obstet Biol Reprod (Paris) 34: S97-102.

22. Mula R, Goncé A, Bennásar M, Arigita M, Meler E, et al. (2012) Increased nuchal translucency and normal karyotype: perinatal and pediatric outcomes at 2 years of age. Ultrasound Obstet Gynecol 39: 34-41.

23. Spencer K (2000) Second-trimester prenatal screening for Down syndrome and the relationship of maternal serum biochemical markers to pregnancy complications with adverse outcome. Prenat Diagn 20: 652-656. 
Citation: Muru K, Vals MA, Sitska M, Asser K, Tammur P, et al. (2013) Outcome of Children with Marked Changes in Maternal Screening Tests and Normal Karyotype. Genetics 3: 123. doi:10.4172/2161-1041.1000123

24. Spencer K, Cowans NJ, Avgidou K, Molina F, Nicolaides KH (2008) Firsttrimester biochemical markers of aneuploidy and the prediction of small-forgestational age fetuses. Ultrasound Obstet Gynecol 31: 15-19.

25. Ilagan JG, Stamilio DM, Ural SH, Macones GA, Odibo AO (2004) Abnormal multiple marker screens are associated with adverse perinatal outcomes in cases of intrauterine growth restriction. Am J Obstet Gynecol 191: 1465-1469.

26. Gagnon A, Wilson RD, Audibert F, Allen VM, Blight C, et al. (2008) Obstetrical complications associated with abnormal maternal serum markers analytes. J Obstet Gynaecol Can 30: 918-949.

27. Hoffman JI, Kaplan S (2002) The incidence of congenital heart disease. J Am Coll Cardiol 39: 1890-1900.

28. Sotiriadis A, Papatheodorou S, Eleftheriades M, Makrydimas G (2013) Nuchal translucency and major congenital heart defects in fetuses with normal karyotype: A meta-analysis. Ultrasound Obstet Gynecol. 42:383-389 